

\title{
MAGNETIC EXCITATIONS AND THE COOPERATIVE JAHN-TELLER TRANSITION IN $\mathrm{PrCu} 2$
}

J. Kjems, H. Ott, S. Shapiro, K. Andres

\section{- To cite this version:}

J. Kjems, H. Ott, S. Shapiro, K. Andres. MAGNETIC EXCITATIONS AND THE COOPERATIVE JAHN-TELLER TRANSITION IN PrCu2. Journal de Physique Colloques, 1978, 39 (C6), pp.C61010-C6-1012. 10.1051/jphyscol:19786446 . jpa-00217924

\section{HAL Id: jpa-00217924 \\ https://hal.science/jpa-00217924}

Submitted on 1 Jan 1978

HAL is a multi-disciplinary open access archive for the deposit and dissemination of scientific research documents, whether they are published or not. The documents may come from teaching and research institutions in France or abroad, or from public or private research centers.
L'archive ouverte pluridisciplinaire HAL, est destinée au dépôt et à la diffusion de documents scientifiques de niveau recherche, publiés ou non, émanant des établissements d'enseignement et de recherche français ou étrangers, des laboratoires publics ou privés. 
MAGNETIC EXCITATIONS AND THE COOPERATIVE JAHN-TELLER TRANSITION IN PrCu 2

\author{
J.K. Kjems ${ }^{\dagger}, H \cdot R \cdot \mathrm{Ott}^{*}, \mathrm{~S} \cdot \mathrm{M} \cdot$ Shapiro**, and K. Andres**** \\ + Risф National Laboratory, DK-4000 Roskilde, Denmark \\ Sumer visitor at Brookhaven National Laboratory 1977 \\ * Laboratorium für Festkörperphysik, EtH, Zürich, Switzerland \\ ** Brookhaven National Laboratory, 11973 New York, USA \\ Research supported by the Division of Basic Energy Sciences, \\ Department of Energy, under contract $N^{\circ} E Y-76-C-02-0016$ \\ 来**ill Laboratories, Murray Hill, 07974 New Jersey, USA
}

\begin{abstract}
Résumé.- La déformation structurelle qui se produit dans $\mathrm{PrCu}_{2}$ au-dessous de 7,3 $\mathrm{K}$ a été déterminée par la diffraction de neutrons. On trouve que la déformation $\mathbf{e}_{\mathbf{z x}}$ de la structure orthorhombique est le paramètre d'ordre primaire. Le couplage de cette déformation aux deux niveaux les plus bas de champ cristallin donne lieu à l'interaction quadrupolaire dominante entre les ions $\mathrm{Pr}^{3+}$. Une transition dipolaire vers le deuxième état excitê est également observée. La dispersion de cette excitation indique que l'interaction d'échange est antiferromagnétique, en accord avec l'ordre antiferromagnétique nucléaire renforcé observé au-dessous de $54 \mathrm{mK}$.
\end{abstract}

Abstract.- The structural distortion in $\mathrm{PrCu}_{2}$ below the Jahn-Teller transition at $\mathrm{T}_{\mathrm{D}}=7.3 \mathrm{~K}$ has been measured by neutron diffraction. The primary order parameter is found to be the $e_{z x}$ strain of the orthorhombic unit cell. A dipole transition to the second excited crystal field level is also observed. The dispersion of this excitation shows that the exchange interaction is antiferromagnetic nuclear ordering reported below $54 \mathrm{mk}$.

1. INTROUCTION.- Structural transitions, which are driven by the cooperative Jahn-Teller effect, are well known for the rare earth insulators like $\mathrm{TmVO}_{4}$, DyVO $_{4}$ and $\mathrm{PrAlO}_{3} / 1,2 /$. The microscopic picture of this class of structural transitions involves phonon-mediated quadrople interactions between the rare earth ions. This interaction mechanism also plays a role in metallic rare earth compounds and among other things it gives rise to the characteristic temperature dependences of the elastic constants in the rare earth chalcogenides/3/. Here we report on a neutron scattering study of a single crystal of $\mathrm{PrCu}_{2}$ in which we have determined the symmetry and the temperature dependence of the structural distortion below the transition at $T_{D}=7.3 \mathrm{~K}$ as well the dispersion of the lowest lying magnetic excitations of this singlet ground-state system.

2. EXPERIMENTAL RESULTS.- The room temperature structure of $\mathrm{PrCu}_{2}$ is orthorhombic ( $\mathrm{a}=4.40 \mathrm{~A}$, $\mathrm{b}=7.02 \AA, c=7.44 \AA$ ) but it can be thought of as a distorted hexagonal $\mathrm{AlB}_{2}$ structure /4/ in which the orthorhombic $b$ axis is the hexagonal axis. The local symmetry at the rare earth site is $C_{2 v}$ which means that the ${ }^{3} \mathrm{H}_{4}$ manifold of the $\mathrm{Pr}^{+3}$ ion is split into nine singlets. The structural phase transition was first observed in specific heat measurements /5/ which indicated a cooperative transition giving rise to an increased splitting of the lowest two, crystal field levels below $\mathrm{T}_{\mathrm{D}}$. This picture was confirmed by the subsequent measurements of the anisotropic susceptibility, the macroscopic strain, sound velocities $/ 3 /$, and crystal field transitions $/ 6 /$. However, the symmetry of the distortion and the nature of the order-parameter were not established.

The sample for the present measurements was grown from the melt by the Bridgeman method in a tantalum crucible. The crystal dimentions were $3 \times 4 \times 7 \mathrm{~mm}^{3}$ and the mosaic width was $1^{\circ}$ (FWHM). The measurements to be reported were carried out partly at the Ris $\phi$ DR3 reactor and partly at the Brookhaven High Flux Beam Reactor. Typical collimations were $40^{\circ}$ and incident energies 13.7 and $5 \mathrm{meV}$ were used.

The distortion below $T_{D}$ was observed with the crystal mounted with the a-c plane in the scattering plane of the spectrometer. We find that the phase transition involves a shear instability along the orthorhombic axes in this plane i.e. it is the elastic constant $C_{55}$ that vanishes. Below $T_{D}$ the distortion gives rise to domain formation which to some extent is obscured by the considerable mosaic width. However, the reciprocal vectors (hOl) and (h0人) no longer have the same length and this results in a measurable splitting of the (101) peaks 


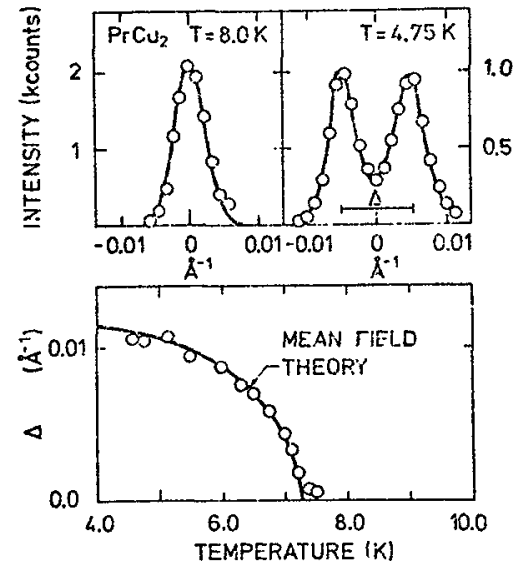

Fig. I : The upper part shows high resolution scans through the (101) Bragg peak at two different temperatures. In the lower part the observed splitting, $\Delta$, is plotted versus temperature. The full line represents a mean field calculation as described in the text.

below $T_{D}$. In figure 1 is shown the results of high resolution scans through the (101) Bragg peak at $8 \mathrm{~K}$ and at $4.75 \mathrm{~K}$. The observed splitting, $\Delta$, is proportional to the increment of the crystallographic angle $B$, and at $4.75 \mathrm{~K}$ we find $\Delta=0.011 \AA^{-1}$ and $B=90^{\circ} .40 \pm 0.5$. The distortion was followed as a function of temperature and the results are shown in the lower part of figure 1.

An intense crystal field transition is observed when the momentum transfer is directed along the $b^{*}$ and $c^{*}$ axes. This transition is completely unaffected by the phase transition at $7.3 \mathrm{~K}$. The absence of this transition for momentum transfer along the $\mathrm{a}^{*}$ axis uniquely defines it as an $\mathrm{s}^{\mathrm{X}}$ transition. Most of the peaks corresponding to this resonance have structure and at certain points in reciprocal space they split into two peaks. Measurements in several zones show that 1) the integrated intensity follows the $\mathrm{Pr}^{+3}$ form factor 2) this mode shows a Davidov splitting i.e. it has two branches because of the interactions between the two ions in the unit cel1 $/ 7 /$, and 3 ) the overall trend of the dispersion of these modes is antiferromagnetic i.e. the energy is lowest at the zone boundary. The observed dispersion along $c^{*}$ is shown in figure 2 .

3. DISCUSSION.- All the available experimental evidence indicates that $\mathrm{PrCu}_{2}$ undergoes a cooperative Jahn-Teller transition at $\mathrm{T}_{\mathrm{D}}=7.3 \mathrm{~K}$ in which the primary order parameter is the $e_{x z}$ strain and which involves only the lowest crystal field levels. From

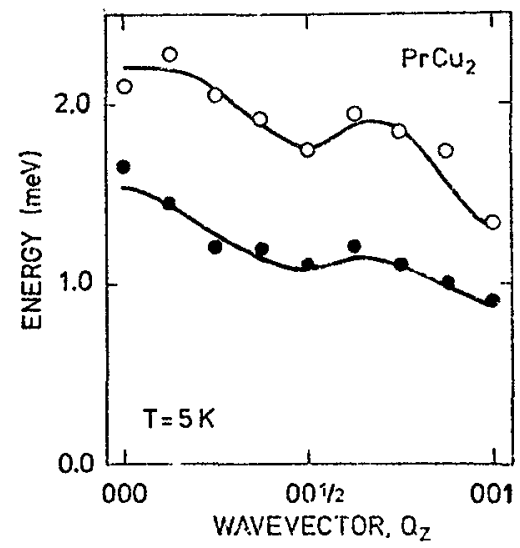

Fig. 2 : The observed dispersion of the $\mathrm{S}^{\mathrm{x}}$-crystal field transition from the ground state to the second excited state. The unit cell contains two rare earth ions and the interaction causes the splitting into two branches.

the analogy with the rare earth insulators we know that the responsible quadrupole interaction partly is mediated by the strain and the acoustic phonons and partly by the optical phonons and other mechanisms. We can estimate the relative importance of these contributions from the observed transition temperature, the saturation distortion and the crystal field splittings. We find that a total interaction corresponding to $8.5 \mathrm{k} /$ ion is needed to drive the transition and of this $5 \mathrm{~K} /$ ion originates from the coupling to the $e_{x z}$ strain. This is in good agreement with the conclusion drawn from the temperature dependence of $\mathrm{C}_{55} / 3 /$. Using these coupling parameters one can calculate the expected temperature dependence of the order parameter and the full curve in the lower part of figure 1 is the result of such a calculation.

The observed dispersion of the $\mathrm{S}^{\mathrm{x}}$ transitions can be represented by a model which contains 5 exchange parameters and the full lines in figure 2 are the results of such a fit. However, the same mode1 only gives a poor representation of the observed structure factor variation which indicates that the magnetic interactions are of much longer range. The antiferromagnetic character of this interaction is consistent with the observation of antiferromagnetic nuclear ordering due to the enhanced electronic susceptibility which has been observed by Andres et al./9/ below $54 \mathrm{mK}$. This aspect is being investigaded further. 


\section{$\underline{\text { References }}$}

11/ Gehring, G.A. and Gehring, K.A., Rep.Prog.Phys. 38 (1975) 1

12/ Kjems, J.K., Crystal Field Effects in Metals and Alloys, Plenum, New York (1977) p. 174

13/ OtE, H.R., Andres, K., Wand, P.S., Wong, Y.H., and Lüthi, B., Crystal Field effects in Metals and Alloys, Plenum, New York (1977) p. 84 and Lüthi B., ibid. p. 104

14/ Storm, A.R., and Benson, K.E., Acta Cryst. 16 (1963) 701

15/ Wun, M., and Phillips, N.E., Phys.Letters 50A (1974) 195

16/ Ott, H.R., Kjems, J.K., and Andres, K., Proceedings of the conference on Rare Earth and Actinides, Durham 1977

/7/ Gehring, G.A., J. Phys. C 7 (1974) L 379

/8/ Cowley, R.A., Phys.Rev. B13 (1976) B13

19/ Andres, K., Bucher, E., Maita, J.P., and Cooper, A.S., Phys.Rev.Lett. 28 (1972) 1652 